\title{
Modified ticagrelor loading doses according to the vasodilator-stimulated phosphoprotein phosphorylation index improve the clinical outcome in ST-elevation myocardial infarction patients with high on-treatment platelet reactivity
}

\author{
Yaling Liu ${ }^{1}$, Sheng Kang ${ }^{2}$, Xiaolin $\mathrm{Li}^{3}$, Zhongwen Liu ${ }^{3}$, Yang $\mathrm{Gao}^{2}$, Xiaodong Wang ${ }^{2}$ \\ ${ }^{1}$ Department of Anesthesiology, Renji Hospital, School of Medicine, \\ Shanghai Jiaotong University, Shanghai, China \\ ${ }^{2}$ Department of Cardiology, Shanghai East Hospital, \\ School of Medicine, Tongji University, Shanghai, China \\ ${ }^{3}$ Department of Cardiology, Shanghai East Hospital (Ji'an Campus), \\ School of Medicine, Jinggangshan University, Ji'an, China
}

\begin{abstract}
Background: Current guidelines recommend a standard ticagrelor loading dose (LD) in ST-segment elevation myocardial infarction (STEMI) patients. However, antiplatelet therapy in STEMI patients at high risk of thrombotic events is suboptimal. The study was conducted to validate whether vasodilatorstimulated phosphoprotein (VASP)-guided ticagrelor dosing individual therapy may result in more effective platelet inhibition and better clinical outcomes.

Methods: This trial included 374 STEMI patients with a low platelet response after ticagrelor $L D$. The patients were randomized into a control group and a VASP-guided group, where the ticagrelor pretreatment was individually adjusted before and after percutaneous coronary intervention (PCI) to obtain a VASP index $<50 \%$. Up to 2 additional boluses of ticagrelor (every additional dosing was $90 \mathrm{mg}$ ) were prescribed after the first LD, and the VASP index was assessed 2 hours after each administration until a VASP index < 50\% was obtained or up to 3 dosages $(360 \mathrm{mg}$ ). The primary endpoint was major adverse cardiovascular events (MACEs) at 30 days. The secondary endpoints were thrombolysis in myocardial infarction (TIMI) major and minor bleeding.

Results: The characteristics were similar in the two groups. After the ticagrelor doses increased, the platelet reactivity index (PRI) decreased, and $98.4 \%$ of patients reached PRI $<50 \%$ in the VASP-guided group. The adenosine concentration increased, and the rate of MACE was significantly lower in the VASP-guided group (10 [5.3\%] vs. 20 [10.8\%], hazard ratio 2.38, 95\% confidence interval 1.21-3.28, $p=0.007$ ). There were no major hemorrhagic complications ( 0 vs. $0, p=1.0)$. The rate of minor bleeding in the VASP-guided group was higher than that in the control group, but the difference was not significant (24 [12.8\%] vs. 16 [8.6\%], $p=0.068)$.

Conclusions: The incremental ticagrelor dosing strategy decreases the rate of MACE after PCI without increasing major and minor bleeding. (Cardiol J)

Key words: ticagrelor, vasodilator-stimulated phosphoprotein, platelet reaction index, ST-segment elevation myocardial infarction, primary percutaneous coronary intervention
\end{abstract}

Address for correspondence: Dr. Xiaodong Wang, Department of Cardiology, Shanghai East Hospital, School of Medicine, Tongji University, Shanghai, China, e-mail: 1978wangxiaodong@163.com

Received: 10.01.2021 Accepted: 23.08.2021 Early publication date: 23.09.2021

Yaling Liu and Sheng Kang contributed equally to this work.

This article is available in open access under Creative Common Attribution-Non-Commercial-No Derivatives 4.0 International (CC BY-NC-ND 4.0) license, allowing to download articles and share them with others as long as they credit the authors and the publisher, but without permission to change them in any way or use them commercially. 


\section{Introduction}

P2Y12 antagonist prasugrel and ticagrelor have been recommended for ST-segment elevation myocardial infarction (STEMI) patients undergoing primary percutaneous coronary intervention (PCI) in current guidelines [1, 2]. However, some STEMI patients have thrombotic risk because of inadequate antithrombotic therapy several hours after PCI. The PLATO study [3] demonstrated that the reversible adenosine diphosphate (ADP) receptor antagonist ticagrelor reduced the primary endpoints compared to clopidogrel in acute coronary syndrome (ACS) patients undergoing PCI. Ticagrelor acts directly on the P2Y12 receptor with no need for previous metabolic activation, which provides faster platelet inhibition than clopidogrel $[4,5]$. In stable coronary artery disease or ACS patients, a $180-\mathrm{mg}$ loading dose (LD) of ticagrelor obviously inhibits the platelet reactivity, and most patients manifest adequate platelet inhibition within 1 hour below the cut-off point $[4,6]$. However, researchers recently reported a delayed onset of ticagrelor antiplatelet action during the first 2 hours in STEMI patients. A higher LD of ticagrelor may be effective to overcome the high on-treatment platelet reactivity during the first 2 hours of STEMI [7]. Furthermore, we can argue that ticagrelor LD is only a daily dose, whereas clopidogrel LD is 4- or 8-fold the long-term daily dose. Oral ticagrelor is safe and well tolerated in healthy subjects at doses up to $400 \mathrm{mg}$ daily [8]. Moreover, in the DISPERSE 2 trial, $270 \mathrm{mg} \mathrm{LD}$ of ticagrelor and a subsequent $360 \mathrm{mg}$ daily dose were not associated with a significant increase in major bleeding events compared with standard ticagrelor administration [9]. Because the high-dose strategy of ticagrelor is safe, we hypothesize that incremental ticagrelor dosing may result in faster and more effective platelet inhibition than standard LD. Thus, in the present study, we compared the vasodilator-stimulated phosphoprotein (VASP)-guided ticagrelor dosing with standard ticagrelor LD regarding their effect on the P2Y12 platelet receptor inhibition and clinical outcomes.

\section{Methods}

Patient recruitment, grouping, and randomization

A single-center, prospective, randomized study was conducted in the Cardiology Department of Shanghai East Hospital, School of Medicine, Tongji University. The study protocol was in accordance with the Declaration of Helsinki and approved by the local ethics committee of our institution. Informed consent was obtained from all participants. The inclusion criterion was the need for PCI with stent implantation for STEMI. The exclusion criteria were platelet reactivity index (PRI) $<50 \%$ after the first ticagrelor LD, cardiac shock, cardiac arrest, New York Heart Association (NYHA) functional class III or IV, contraindications to antiplatelet therapy, platelet count $<100 \times$ $\times 10^{9} / \mathrm{L}$, bleeding diathesis or upper gastrointestinal hemorrhage, warfarin or other oral anticoagulant therapy, creatinine clearance $<25 \mathrm{~mL} / \mathrm{min}$, surgery within 1 month or scheduled in the following year, and concurrent severe illness with expected survival of $<1$ year.

The participants were allocated into a VASP-guided group and a control group according to the first VASP index (PRI > 50\%). Randomization was performed in a permuted block size of 4 using an automatically created randomization system called an interactive web-based response.

The present study was prospectively registered in the Chinese Clinical Trial Registry, a Primary Registry of the International Clinical Trial Registry Platform, World Health Organization (Registration no. ChiCTR-IOR-17013854). The registered date was December 11, 2017.

\section{Angioplasty procedure}

Percutaneous coronary intervention was conducted according to international guidelines using a standard technique through the radial or femoral route [2]. A drug-eluting stent (DES) was used according to the European Society of Cardiology guidelines [10]. An IV bolus of unfractionated heparin $(100 \mathrm{IU} / \mathrm{kg})$ was administered at the beginning of the procedure. The sheath was immediately removed after the procedure via the radial approach and 6 hours later via the femoral approach. A combination of $300 \mathrm{mg}$ acetylsalicylic acid (ASA) and $180 \mathrm{mg}$ ticagrelor LD was administered immediately after the acute myocardial infarction (MI) diagnosis. Afterwards, the combination administration of $100 \mathrm{mg}$ QD ASA and $90 \mathrm{mg}$ BID ticagrelor continued for at least 1 year. Glycoprotein IIb/IIIa inhibitors (GPIs) were determined by interventional cardiologists. In brief, to avoid increasing bleeding and interaction with ticagrelor, GPI was only allowed when there was too much thrombus. The interventional cardiologist and treating physician were not aware of the VASP index results or group assignment during PCI. 


\section{Ticagrelor modification}

The VASP index was measured $\geq 2$ hours after the first $180 \mathrm{mg} \mathrm{LD}$ of ticagrelor. All patients with a VASP index $>50 \%$ were prospectively included in the study and randomly assigned to the control group or VASP-guided group. In the control group, PCI was conducted without an additional bolus of ticagrelor. In the VASP-guided group, the ticagrelor pretreatment was individually adjusted before and after PCI to obtain a VASP index $<50 \%$. Additional ticagrelor doses (90 $\mathrm{mg}$ each) were administered every 2 hours after the first LD until $360 \mathrm{mg}$ ticagrelor was reached, i.e., $180 \mathrm{mg} \mathrm{LD}$ and twice incremental 90-mg doses. Briefly, up to 2 additional $90 \mathrm{mg}$ doses of ticagrelor were prescribed after the previous LD, and the VASP index was assessed 2 hours after each administration until a VASP index $<50 \%$ was obtained. Therefore, the maximum dose of ticagrelor was $360 \mathrm{mg}$. In the control group, a placebo was administered at each loading phase.

\section{Blood samples}

Blood samples of $10 \mathrm{~mL}$ for the VASP index analysis were drawn by atraumatic venipuncture of the antecubital vein at least 2 hours after each ticagrelor dosing. The initial blood drawn was discarded to avoid measuring the platelet activation induced by needle puncture. Blood was collected in a vacutainer (Becton Dickinson Company, Franklin Lakes, NJ, USA) containing 3.8\% trisodium citrate and filled to capacity. The vacutainer was inverted 3-5 times for gentle mixing and immediately sent to the hemostasis laboratory. In the control group, the number of times that the VASP samples were drawn was related to the VASP-guided group.

\section{VASP phosphorylation analysis}

The VASP index phosphorylation analysis was conducted within 2 hours of blood collection by an experienced investigator using platelet VASP kits (from BioCytex, Marseille, France) according to the manufacturer's instructions [11]. The ratio $\left[\left(\mathrm{MFI}_{\mathrm{PGE} 1}-\mathrm{MFI}_{\mathrm{ADP}+\mathrm{PGE} 1}\right) / \mathrm{MFI}_{\mathrm{PGE}}\right] \times 100 \%$ is $\mathrm{ex}-$ pressed in this study as the PRI, which corresponds to a ratio of the VASP phosphorylation of activated platelets vs. resting platelets and is expressed as a percentage of the platelet reactivity.

\section{Adenosine plasma concentration measurement}

Blood samples $(3 \mathrm{~mL})$ were collected by an atraumatic venipuncture of the antecubital vein on admission and processed. Fresh whole blood was collected in tubes containing a stop solution that prevented red blood cell uptake and degradation of adenosine. After centrifugation, the supernatants were deproteinized, and adenosine was measured using high-performance liquid chromatography [12].

\section{Clinical endpoints}

Clinical follow-up was initiated immediately after PCI and terminated 1 month later. The endpoints were recorded by an investigator blinded to the patients' treatment status and clinical characteristics. The primary endpoint was the rate of major adverse cardiovascular events (MACEs) and dyspnea. MACE included target vessel revascularization (TVR), stent thrombosis (ST), nonfatal MI, and cardiovascular death at 1 month. TVR was defined as repeated PCI or coronary artery bypass grafting (CABG). ST was defined according to the Academic Research Consortium (ARC) [13]. Nonfatal MI was defined as recurrent ischemic symptoms (> $20 \mathrm{~min}$ ) and/or electrocardiographic changes after PCI with an increase $>20 \%$ in troponin measured after the recurrent event with at least 1 value above the $99^{\text {th }}$ percentile of the reference range [14]. All deaths were considered cardiovascular deaths unless the definite reason was verified. The level of dyspnea was assessed using the modified Medical Research Council (MRC) scale [15]. The secondary endpoints were major and minor bleeding. Major bleeding was defined as intracranial bleeding or clinically overt bleeding associated with a $50-\mathrm{g} / \mathrm{L}$ decrease in hemoglobin according to the Thrombolysis in Myocardial Infarction (TIMI) criteria [16]. Minor bleeding was also defined according to the TIMI criteria [16]. An independent clinical event committee was blinded to the treatment allocation.

\section{Power calculation}

We postulated that the average difference in MACE rate between the two groups would be $15 \%$ [14]. Therefore, for $90 \%$ power and an alpha risk of $5 \%$, we estimated that 180 patients should be included in each group. We estimated that $5 \%$ of patients would be lost to follow-up, so the target number of included patients was 378 .

\section{Ethical approval}

The study protocol was in accordance with the Declaration of Helsinki and was approved by the Ethics Committee of Shanghai East Hospital. Written informed consent was obtained from study participants. 


\section{Statistical analysis}

Statistical analysis was conducted using the SPSS 17.0 software (SPSS Inc., Chicago, IL, USA). Continuous variables are expressed as the mean \pm standard deviation and were tested for normality of distribution. Categorical variables are expressed as frequencies and percentages. Analysis of variance was used to compare the quantitative variables. Categorical variables were compared using the chi-squared test or Fisher's exact test when the frequencies were below 5 . Kaplan-Meier curves were used to assess the MACE-free survival. Differences between the curves were tested with a log-rank statistic. A p value $<0.05$ was considered significant.

\section{Results}

Patient demographic, biological, and angiographic characteristics

In total, 1037 patients were included in the prospective study in the Department of Cardiology in the Shanghai East Hospital, School of Medicine, Tongji University from July 2018 to July 2019 (Fig. 1); 41 patients were excluded. PRI $<50 \%$ was demonstrated in 647 patients, who were considered good responders and excluded. In total, 390 included patients manifested PRI $>50 \%$ and were randomly divided into the control group or the VASP-guided group $(\mathrm{n}=195)$. Finally, $374(95.9 \%)$ patients finished the 30-day follow-up (Fig. 1).

The baseline characteristics are summarized in Table 1. Demographic data and clinical characteristics were balanced between the two groups. All patients underwent PCI. The PCI data were also similar.

\section{Platelet reactivity index}

The mean time between the LD of ticagrelor and the blood sampling was similar in the two groups $(116 \pm 42$ min vs. $124 \pm 55 \mathrm{~min}, \mathrm{p}=0.70$; Table 1). The VASP index in the control group after ticagrelor LD was higher than that in the VASP-guided group, but the difference was not significant $(85.4 \pm 16.2$ vs. $79.3 \pm 13.1, p=0.22)$. Table 2 summarizes the effect of each additional ticagrelor dosing on the PRI and the patient partition of VASP $<50 \%$ after each ticagrelor dosing in the two groups. In the VASP-guided group, after the first and second incremental ticagrelor doses, $95(50.5 \%)$ and $139(74.1 \%)$ patients had a VASP index below $50 \%$, and the average VASP indices after the first and second ticagrelor incremental doses were $48.5 \pm 9.4 \%$ and $36.9 \pm 5.8 \%$, re-

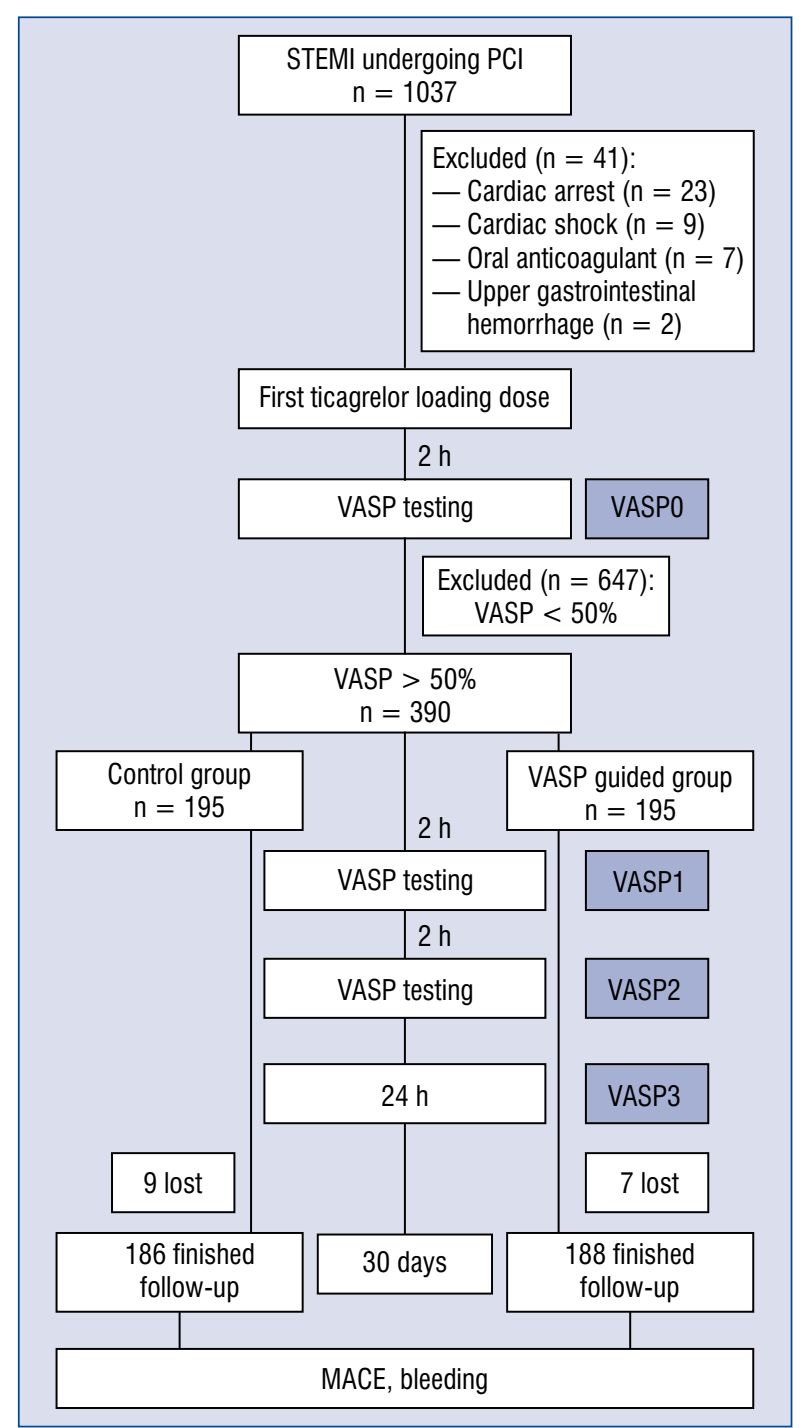

Figure 1. Study design chart; MACE - major adverse cardiac events; $\mathrm{PCl}$ - percutaneous coronary intervention; STEMI — ST-segment elevation myocardial infarction; VASP — vasodilator-stimulated phosphoprotein.

spectively ( $\mathrm{p}<0.01$ vs. after the LD). Eventually, 24 hours after LD, the incremental ticagrelor dosing gave most patients $(185 / 188,98.4 \%)$ a VASP index below $50 \%$ (the VASP index was $19.5 \pm$ $\pm 7.3 \%, \mathrm{p}<0.01$ vs. baseline). In the control group, only $127(68.3 \%)$ patients reached PRI $<50 \% 24$ hours after LD. The VASP index difference was not significant among the 3 measurement time points $(57.9 \pm 10.0 \%$ vs. $42.8 \pm 9.7 \%$ vs. $40.3 \pm$ $\pm 9.4 \%, \mathrm{p}>0.05)$.

\section{Plasma adenosine concentration}

The plasma adenosine concentration in the control group increased more than that at baseline but did not dramatically change during the 30-day 
Table 1. Baseline characteristics.

\begin{tabular}{|c|c|c|c|}
\hline Characteristics & $\begin{array}{l}\text { Control group } \\
(\mathrm{n}=186)\end{array}$ & $\begin{array}{l}\text { VASP-guided group } \\
\text { (n=188) }\end{array}$ & $\mathbf{P}$ \\
\hline Age [year] & $65.3 \pm 9.8$ & $64.6 \pm 10.2$ & 0.82 \\
\hline Men & $104(55.9 \%)$ & $98(52.1 \%)$ & 0.79 \\
\hline BMI $\left[\mathrm{kg} / \mathrm{m}^{2}\right]$ & $26.3 \pm 5.1$ & $27.4 \pm 8.2$ & 0.54 \\
\hline Myocardial infarction history & $32(17.3 \%)$ & $36(19.2 \%)$ & 0.91 \\
\hline CABG history & $1(0.5 \%)$ & $3(1.6 \%)$ & 0.10 \\
\hline \multicolumn{4}{|l|}{ Cardiovascular risk factors: } \\
\hline Hypertension & $79(42.7 \%)$ & $94(50.1 \%)$ & 0.69 \\
\hline Diabetes mellitus & $93(50.0 \%)$ & $88(46.8 \%)$ & 0.48 \\
\hline Dyslipidemia & $92(49.3 \%)$ & $89(47.2 \%)$ & 0.64 \\
\hline Current smoking & $109(58.6 \%)$ & $100(53.1 \%)$ & 0.77 \\
\hline Family history of CAD & $30(16.3 \%)$ & $43(22.7 \%)$ & 0.28 \\
\hline \multicolumn{4}{|l|}{ Treatment on admission: } \\
\hline ASA & $174(93.6 \%)$ & $180(95.7 \%)$ & 0.7 \\
\hline Beta-blocker & $90(48.6 \%)$ & $95(50.5 \%)$ & 0.93 \\
\hline ACEI or ARB & $137(73.5 \%)$ & $141(75.2 \%)$ & 0.87 \\
\hline Calcium antagonist & $27(14.3 \%)$ & $24(12.6 \%)$ & 0.72 \\
\hline Statin & $186(100 \%)$ & $188(100 \%)$ & 1.00 \\
\hline Morphine use & $65(35 \%)$ & $56(30 \%)$ & 0.65 \\
\hline GPI & $15(8.2 \%)$ & $15(8.0 \%)$ & 0.89 \\
\hline LVEF [\%] & $56.8 \pm 12.4$ & $54.3 \pm 13.6$ & 0.55 \\
\hline \multicolumn{4}{|l|}{$\mathrm{PCl}$ procedure: } \\
\hline Femoral artery & $88(47.5 \%)$ & $96(51.3 \%)$ & 0.69 \\
\hline Number of diseased vessels & $2.3 \pm 0.8$ & $2.2 \pm 1.5$ & 0.48 \\
\hline Number of treated vessels & $1.8 \pm 0.9$ & $1.5 \pm 0.4$ & 0.65 \\
\hline Drug eluting stent & $186(100 \%)$ & $188(100 \%)$ & 0.91 \\
\hline Stent length per patient [mm] & $31.2 \pm 2.8$ & $29.5 \pm 4.3$ & 0.58 \\
\hline Average stent width [mm] & $2.9 \pm 0.8$ & $3.1 \pm 1.5$ & 0.73 \\
\hline Number of stents per patient & $1.8 \pm 0.6$ & $2.2 \pm 1.3$ & 0.13 \\
\hline LAD & $109(58.6 \%)$ & $94(50.0 \%)$ & 0.16 \\
\hline LCX & $23(12.4 \%)$ & $37(19.7 \%)$ & 0.25 \\
\hline RCA & $54(29.0 \%)$ & $57(30.3 \%)$ & 0.88 \\
\hline \multicolumn{4}{|l|}{ Biology: } \\
\hline VASP before PCI [\%] & $85.4 \pm 16.2$ & $79.3 \pm 13.1$ & 0.22 \\
\hline Time between hospital admission and first LD [min] & $42.8 \pm 10.5$ & $44.1 \pm 11.2$ & 0.70 \\
\hline Time between the first LD and blood sampling & $116 \pm 42$ & $124 \pm 55$ & 0.93 \\
\hline Hemoglobin $[\mathrm{g} / \mathrm{L}]$ & $13.9 \pm 5.2$ & $13.2 \pm 2.8$ & 0.84 \\
\hline Platelets $\left[10^{9} / \mathrm{L}\right]$ & $189 \pm 27$ & $201 \pm 56$ & 0.49 \\
\hline Creatinine $[\mathrm{mg} / \mathrm{dL}]$ & $0.77 \pm 0.21$ & $0.79 \pm 0.36$ & 0.53 \\
\hline Fibrinogen $[\mathrm{g} / \mathrm{L}]$ & $3.5 \pm 1.4$ & $3.8 \pm 2.1$ & 0.12 \\
\hline
\end{tabular}

ASA - acetylsalicylic acid; ACEI — angiotensin converting enzyme inhibitor; ARB — angiotensin receptor blocker; BMI — body mass index; CABG - coronary artery bypass grafting; CAD - coronary artery disease; GPI - glycoprotein Ilb/lla inhibitors; LAD - left anterior descending; LCX — left circumflex; LD — loading dose; LVEF — left ventricular ejection fraction; PCI — percutaneous coronary intervention; RCA — right coronary artery; VASP — vasodilator-stimulated phosphoprotein

follow-up, whereas in the VASP-guided group the adenosine concentration significantly increased when the ticagrelor incremental dose increased (Table 2). 
Table 2. Continuous vasodilator-stimulated phosphoprotein (VASP) index, patient partition of VASP $<50 \%$, and adenosine concentration after each ticagrelor loading dose.

\begin{tabular}{lccccc}
\hline Groups and variables & VASP0 & VASP1 & VASP2 & VASP3 & P \\
\hline Control group $(\mathbf{n}=\mathbf{1 8 6})$ & & & & & $>0.05$ \\
VASP index [\%] & $85.4 \pm 16.2$ & $57.9 \pm 10.0$ & $42.8 \pm 9.7$ & $40.3 \pm 9.4$ & $>0.05$ \\
Patients with VASP index $<50 \%$ & $0(0 \%)$ & $90(48.3 \%)$ & $110(59.3 \%)$ & $127(68.3 \%)$ & $>0.05$ \\
Adenosine $[\mu \mathrm{g} / \mathrm{L}]$ & $62.6 \pm 11.7$ & $98.4 \pm 17.5$ & $108.4 \pm 14.1$ & $116 \pm 18.5$ & $>0.5$ \\
VASP-guided group $(\mathbf{n}=\mathbf{1 8 8})$ & & & & $19.5 \pm 7.3$ & $<0.01$ \\
VASP index [\%] & $79.3 \pm 13.1$ & $48.5 \pm 9.4$ & $36.9 \pm 5.8$ & $185(98.4 \%)$ & $<0.01$ \\
Patients with VASP index $<50 \%$ & $0(0 \%)$ & $95(50.5 \%)$ & $139(74.1 \%)$ & $185 \pm 16.6$ & $<0.01$ \\
Adenosine $[\mu \mathrm{g} / \mathrm{L}]$ & $64.3 \pm 10.5$ & $125.6 \pm 19.7$ & $147.2 \pm 15.8$ & 185.
\end{tabular}

VASP 0-3 - VASP index before the percutaneous coronary intervention baseline measurement, 2 hours after the first additional dosing measurement, 2 hours after the second additional dosing measurement, and 24 hours after the percutaneous coronary intervention measurement

Table 3. Primary and secondary endpoints during the 1-month follow-up.

\begin{tabular}{|c|c|c|c|}
\hline Endpoints & $\begin{array}{l}\text { Control group } \\
(n=186)\end{array}$ & $\begin{array}{l}\text { VASP-guided group } \\
\text { (n=188) }\end{array}$ & $\mathbf{P}$ \\
\hline Target vessel revascularization & $8(4.3 \%)$ & $5(2.7 \%)$ & 0.045 \\
\hline Stent thrombosis at 1 month: & $3(1.6 \%)$ & $1(0.5 \%)$ & 0.032 \\
\hline Definite & $2(1.0 \%)$ & $1(0.5 \%)$ & \\
\hline Probable & $1(0.5 \%)$ & $0(0 \%)$ & \\
\hline Possible & $0(0 \%)$ & $0(0 \%)$ & \\
\hline Nonfatal myocardial infarction & $6(3.2 \%)$ & $4(2.1 \%)$ & 0.033 \\
\hline Cardiac death & $3(1.6 \%)$ & $0(0 \%)$ & 0.021 \\
\hline All MACE & $20(10.8 \%)$ & $10(5.3 \%)$ & 0.007 \\
\hline Dyspnea & $24(12.9 \%)$ & $34(18.1 \%)$ & 0.019 \\
\hline Major bleeding & $0(0 \%)$ & $0(0 \%)$ & 1.0 \\
\hline Minor bleeding & $16(8.6 \%)$ & $24(12.8 \%)$ & 0.068 \\
\hline
\end{tabular}

MACE - major adverse cardiac events

\section{Clinical endpoints}

A 30-day follow-up was completed in 374 (95.9\%) patients. During follow-up, 20 (10.8\%) MACEs in the control group and $10(5.3 \%)$ MACEs in the VASP-guided group occurred, which resulted in a significant difference between the two groups $(\mathrm{p}=0.007)$. The distribution of cardiovascular events is summarized in Table 3. Dyspnea occurred more frequently in the VASP-guided group than in the control group ( $18.1 \%$ vs. $12.9 \%, \mathrm{p}=0.019)$. No dyspnea-intolerant patients withdrew from the study. There were no major hemorrhagic complications in any group. The rate of minor bleeding in the VASP-guided group was higher than that in the control group, but the difference was not significant $(12.8 \%$ vs. $8.6 \%, \mathrm{p}=0.068)$. No other side effects of ticagrelor (bradycardia, atrioventricular block, ventricular pause, or atrial fibrillation) were reported (Table 3 ).

\section{Kaplan-Meier analysis}

As Figure 2 shows, cumulative survival in the two groups was distinguished by the Kaplan-Meier curve. Cardiovascular event-free survival was higher in the VASP-guided group than in the control group. The difference was significant (0 vs. 3 , log-rank 5.613, $\mathrm{p}=0.028$ ).

\section{Discussion}

This study suggests that modified ticagrelor incremental dosing according to the VASP index improves the platelet reactivity and clinical outcomes in STEMI patients undergoing PCI. This ticagrelor incremental dosing strategy is safe and is not associated with an unacceptable bleeding complication rate. To the best of our knowledge, this is the first randomized study to demonstrate the clinical benefit of prospective platelet monitoring 


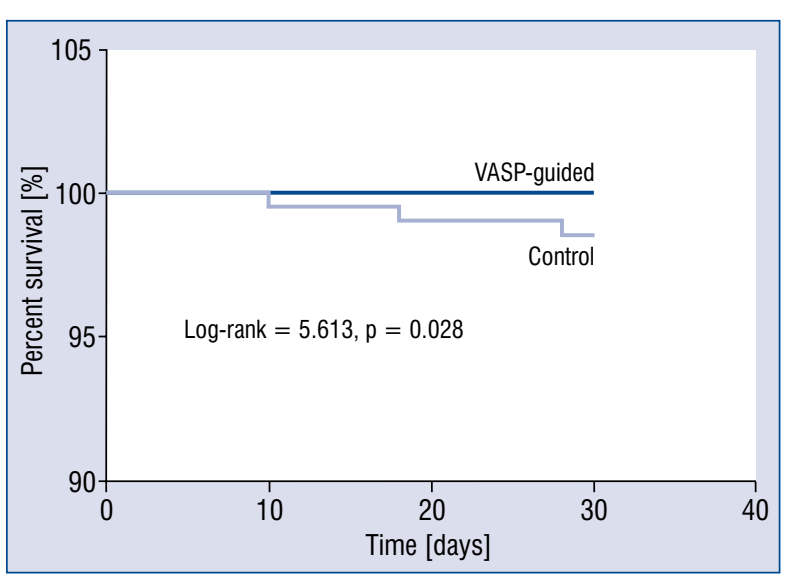

Figure 2. Kaplan-Meier analysis of 30-day survival; VASP — vasodilator-stimulated phosphoprotein.

of the ticagrelor efficiency in patients undergoing stenting.

Incremental ticagrelor dosing increased platelet inhibition compared with standard $180-\mathrm{mg}$ LD. Two hours after the first ticagrelor LD, approximately half of the patients still had high on-treatment platelet reactivity despite the use of highly effective antiplatelet agents in both the VASP-guided group and the control group. Two hours after the second additional dosing, approximately two-thirds of patients in the VASP-guided group showed optimal platelet inhibition. At least 3 incremental doses were required to achieve optimal platelet inhibition in most patients. Conversely, in a nonrandomized study by Alexopoulos et al. [17], the residual platelet reactivity values obtained by a double $360-\mathrm{mg}$ ticagrelor $\mathrm{LD}$ were similar to the standard 180-mg LD. However, the study was purely pharmacodynamic, did not allow any conclusions on clinical outcomes, and had a small sample size (83 patients). The lack of pharmacokinetic data did not elucidate the exact mechanisms responsible for the double LD delayed onset of action of ticagrelor. In another study of ticagrelor escalating loading dose in STEMI patients [18], increasing LD regimens failed to overcome an impaired response to ticagrelor, which indicates a delay in drug absorption, in contrast to our study. The discrepancy may account for racial differences and a small sample that could not identify the clinical effect.

In STEMI patients, the drug absorption speed plays a dominant role during the action of new oral antiplatelet agents. In this spectrum of patients, nausea and vomiting, which resulted from an imbalance of sympathetic and vagus function, hemodynamic disturbance, extensive vasocon- striction, sympathetic activation, and morphine use significantly affected the drug onset of action. A study verified the effect of morphine use on the delayed antiplatelet effect [19]. However, in the present study, the specific type of delay in orally administered drug action was overcome by increasing the incremental doses of ticagrelor. The discrepancy might be attributed to ethics and lack of morphine use.

In the MOJITO study [20], crushed ticagrelor tablet administration in STEMI patients was feasible and provided earlier platelet inhibition than standard integral tablets. However, in the IPAAD-Tica study [21], chewed ticagrelor tablets resulted in significant platelet activity inhibition compared to crushed or integral tablets at 20 and $60 \mathrm{~min}$. These studies indicate that the ticagrelor dosing peri-PCI is not fixed, and absorption is related to platelet inhibition.

Ticagrelor is a powerful ADP receptor antagonist, and is more effective in the treatment of atherothrombosis. Previous studies indicated that ticagrelor inhibited ADP-induced $\mathrm{Ca}^{2+}$ release compared to other P2Y12 receptor antagonists. The extra P2Y12 receptor inhibition of ticagrelor might be due to equilibrative nucleoside transporter 1 (ENT1) antagonism on platelets. ENT1 inhibition increased the concentration of extracellular adenosine and activated Gs-coupled adenosine $\mathrm{A}_{2} \mathrm{~A}$ receptors [22]. Because more ticagrelor was used in the VASP-guided group, more ENT1 receptor was inhibited and the adenosine concentration increased, which resulted in more dyspnea in the VASP-guided group. In addition, ticagrelor reduced the rat myocardial infarct size, and the protective effect of ticagrelor depended on the adenosine receptor activation with downstream upregulation of endothelial nitric oxide synthase and cyclooxygenase $(\mathrm{COX})_{2}$ activity [23]. This protective effect was demonstrated in the CvLPRIT--CMR study [24]; ticagrelor was associated with a smaller infarct size and lower microvascular obstruction than clopidogrel for STEMI.

The MACE discrepancies in similar Unites States and European studies occurred due to the following: 1) Asian ethnic characteristics: in the PLATO sub-study of Asian patients [25], the overall cardiovascular event rates were higher in Asians, and the primary efficacy endpoint was $12.0 \%$ in the ticagrelor group. Southeast Asians were more prone to develop MACEs than East Asians; 2) Clinical characteristics: In the present study, the percentages of hypertension, diabetes, and dyslipidemia were $46 \%, 48 \%$, and $48 \%$, respectively; 3) The relatively small sample size in our study. 
Only $68.3 \%$ of the patients in the control group had a VASP index $<50 \% 24$ hours after the first ticagrelor loading dose. In a prospective, multicenter observational study of ACS patients undergoing PCI, the platelet reactivity determined by the VASP index was associated with and predicted the occurrence of definite acute stent thrombosis [26].

We observed no bleeding increase in the VASP-guided group despite the use of high ticagrelor incremental dosage, possibly because the platelet monitoring stratifies ticagrelor dosing according to the individual response. This individualization prevented high doses of ticagrelor in patients with good responses. These results are consistent with a meta-analysis in which ticagrelor decreased the MACE risk and stent thrombosis without causing more bleeding events than clopidogrel in STEMI patients undergoing PCI [27]. A PLATO trial substudy showed that only major bleeding was associated with a marked increase in short-term mortality [28]. However, the incidence of major bleeding was not higher with the ticagrelor treatment in the PLATO trial (11.6\% vs. $11.2 \%)$ [3]. Accordingly, in a retrospective cohort study of the nationwide Chinese population, the incidence of major bleeding was comparable between ticagrelor and clopidogrel $(3.2 \%$ vs. $4.1 \%)$ [29]. In a large retrospective study of real-world Chinese patients with ACS treated by PCI, ticagrelor increased all bleeding in patients with moderate to high bleeding risk (4.8\% vs. $1.3 \%)$ but did not increase bleeding in subjects with low bleeding risk ( $1.5 \%$ vs. $0.8 \%$ ) [30]. In the present study, there was no major bleeding in either group, possibly due to the low bleeding risk in patients (who were relatively young, with more hypertension, diabetes, and dyslipidemia) in our study and the limited sample size. More minor bleeding was observed in the VASP-guided group, although the difference was not significant. The reason might have been the incremental ticagrelor dosing, which was used to decrease the PRP $<50 \%$. However, the clinical outcome was safe for two reasons: 1) rigorous platelet activity monitoring and 2 ) East Asian patient inherited characteristics in the local Chinese population study.

In a prospective study in patients undergoing PCI, Bonello et al. [11] demonstrated that a 50\% cutoff value of the VASP index could predict MACEs during a 6-month follow-up. Later, the VASP index was used to adjust clopidogrel LD to decrease the MACE in clopidogrel-resistant patients [31]. In our previous study [32], modified clopidogrel maintenance doses according to the VASP index improved the clinical outcome in patients with clopidogrel resistance. In addition, we tailored the clopidogrel LD according to the VASP index to attenuate the clopidogrel resistance in carriers of $\mathrm{ABCB} 1$ mutant allele in patients undergoing PCI [33]. Because both ticagrelor and clopidogrel are adenosine P2Y12 receptor blockers, we preferred the $50 \%$ VASP index as the cutoff point.

Finally, the cost-effectiveness of the proposed regimen was not evaluated in the present study because this was not the objective of the study. In fact, platelet function-guided antiplatelet therapy has been shown to be superior to fixed dosing on clopidogrel or ticagrelor administration [34]. In the study, the costs were calculated per 1000 patients. VerifyNow P2Y12 assay testing was used to evaluate the platelet activity. The results show that the assessment of residual platelet reactivity with P2Y12 measurement was a cost-effective strategy to reduce financial burden compared to the routine administration of more expensive antiplatelet agents. Based on these results, it may be beneficial to guide ticagrelor dosing peri-PCI according to the VASP index. Nevertheless, the cost effectiveness must be analyzed in the future.

\section{Limitations of the study}

There were several limitations in the present study. The first limitation was the relatively small sample size, which only included 374 patients. Although we recruited more than 1000 patients at the beginning of the study, approximately two-thirds manifested good response to ticagrelor and were excluded, so only 374 patients finished the 30 -day follow-up. According to the statistical power calculation, the target number of included patients was 378 . Nevertheless, the present patient number met the statistical testing power and made a significant difference between the two groups. The second limitation was that all large, randomized trials to investigate platelet function-guided antiplatelet therapy failed to prove superiority. Only the TROPICAL-ACS [35] study showed that the platelet function-guided de-escalation was noninferior to a standard regimen. The findings of this trial warrant further investigation in a larger population of patients.

\section{Conclusions}

The VASP-guided individual ticagrelor incremental dosing strategy improves the clinical outcomes after PCI without increasing major and minor bleeding.

Conflict of interest: None declared 


\section{References}

1. Ibanez B, James S, Agewall S, et al. 2017 ESC Guidelines for the management of acute myocardial infarction in patients presenting with ST-segment elevation: The Task Force for the management of acute myocardial infarction in patients presenting with ST-segment elevation of the European Society of Cardiology (ESC). Eur Heart J. 2018; 39(2): 119-177, doi: 10.1093/eurheartj/ /ehx393, indexed in Pubmed: 28886621.

2. Levine GN, Bates ER, Blankenship JC, et al. 2015 ACC/AHA/ /SCAI Focused Update on Primary Percutaneous Coronary Intervention for Patients With ST-Elevation Myocardial Infarction: An Update of the 2011 ACCF/AHA/SCAI Guideline for Percutaneous Coronary Intervention and the 2013 ACCF/AHA Guideline for the Management of ST-Elevation Myocardial Infarction. J Am Coll Cardiol. 2016; 67(10): 1235-1250, doi: 10.1016/j. jacc.2015.10.005, indexed in Pubmed: 26498666.

3. Wallentin L, Becker RC, Budaj A, et al. Ticagrelor versus clopidogrel in patients with acute coronary syndromes. N Engl J Med. 2009; 361(11): 1045-1057, doi: 10.1056/NEJMoa0904327, indexed in Pubmed: 19717846.

4. Gurbel PA, Bliden KP, Butler K, et al. Randomized doubleblind assessment of the ONSET and OFFSET of the antiplatelet effects of ticagrelor versus clopidogrel in patients with stable coronary artery disease: the ONSET/OFFSET study. Circulation. 2009; 120(25): 2577-2585, doi: 10.1161/CIRCULATIONAHA.109.912550, indexed in Pubmed: 19923168.

5. Giorgi MA, Cohen Arazi H, Gonzalez CD, et al. Beyond efficacy: pharmacokinetic differences between clopidogrel, prasugrel and ticagrelor. Expert Opin Pharmacother. 2011; 12(8): 1285-1295, doi: 10.1517/14656566.2011.550573, indexed in Pubmed: 21254864 .

6. Storey RF, Angiolillo DJ, Patil SB, et al. Inhibitory effects of ticagrelor compared with clopidogrel on platelet function in patients with acute coronary syndromes: the PLATO (PLATelet inhibition and patient Outcomes) PLATELET substudy. J Am Coll Cardiol. 2010; 56(18): 1456-1462, doi: 10.1016/j.jacc.2010.03.100, indexed in Pubmed: 20832963.

7. Alexopoulos D, Xanthopoulou I, Gkizas V, et al. Randomized assessment of ticagrelor versus prasugrel antiplatelet effects in patients with ST-segment-elevation myocardial infarction. Circ Cardiovasc Interv. 2012; 5(6): 797-804, doi: 10.1161/CIRCINTERVENTIONS.112.972323, indexed in Pubmed: 23169985.

8. Teng R, Butler K. Pharmacokinetics, pharmacodynamics, tolerability and safety of single ascending doses of ticagrelor, a reversibly binding oral P2Y(12) receptor antagonist, in healthy subjects. Eur J Clin Pharmacol. 2010; 66(5): 487-496, doi: 10.1007/ s00228-009-0778-5, indexed in Pubmed: 20091161.

9. Cannon CP, Husted S, Harrington RA, et al. DISPERSE-2 Investigators. Safety, tolerability, and initial efficacy of AZD6140, the first reversible oral adenosine diphosphate receptor antagonist, compared with clopidogrel, in patients with non-ST-segment elevation acute coronary syndrome: primary results of the DISPERSE-2 trial. J Am Coll Cardiol. 2007; 50(19): 1844-1851, doi: 10.1016/j.jacc.2007.07.053, indexed in Pubmed: 17980250.

10. Roffi M, Patrono C, Collet JP, et al. 2015 ESC Guidelines for the management of acute coronary syndromes in patients presenting without persistent ST-segment elevation: Task Force for the Management of Acute Coronary Syndromes in Patients Presenting without Persistent ST-Segment Elevation of the European
Society of Cardiology (ESC). Eur Heart J. 2016; 37(3): 267-315, doi: 10.1093/eurheartj/ehv320, indexed in Pubmed: 26320110.

11. Bonello L, Paganelli F, Arpin-Bornet M, et al. Vasodilator-stimulated phosphoprotein phosphorylation analysis prior to percutaneous coronary intervention for exclusion of postprocedural major adverse cardiovascular events. J Thromb Haemost. 2007; 5(8): 1630-1636, doi: 10.1111/j.1538-7836.2007.02609.x, indexed in Pubmed: 17488353.

12. Bonello L, Laine M, Kipson N, et al. Ticagrelor increases adenosine plasma concentration in patients with an acute coronary syndrome. J Am Coll Cardiol. 2014; 63(9): 872-877, doi: 10.1016/j. jacc.2013.09.067, indexed in Pubmed: 24291273.

13. Cutlip DE, Windecker S, Mehran R, et al. Academic Research Consortium. Clinical end points in coronary stent trials: a case for standardized definitions. Circulation. 2007; 115(17): 2344-2351, doi: 10.1161/CIRCULATIONAHA.106.685313, indexed in Pubmed: 17470709.

14. Thygesen K, Alpert J, White H. Universal Definition of Myocardial Infarction. J Am Coll Cardiol. 2007; 50(22): 2173-2195, doi: 10.1016/j.jacc.2007.09.011.

15. Nishiyama O, Taniguchi H, Kondoh Y, et al. A simple assessment of dyspnoea as a prognostic indicator in idiopathic pulmonary fibrosis. Eur Respir J. 2010; 36(5): 1067-1072, doi: 10.1183/09031936.00152609, indexed in Pubmed: 20413545.

16. Rao AK, Pratt C, Berke A, et al. Thrombolysis in Myocardial Infarction (TIMI) Trial--phase I: hemorrhagic manifestations and changes in plasma fibrinogen and the fibrinolytic system in patients treated with recombinant tissue plasminogen activator and streptokinase. J Am Coll Cardiol. 1988; 11(1): 1-11, doi: 10.1016/0735-1097(88)90158-1, indexed in Pubmed: 3121710.

17. Alexopoulos D, Gkizas V, Patsilinakos S, et al. Double versus standard loading dose of ticagrelor: onset of antiplatelet action in patients with STEMI undergoing primary PCI. J Am Coll Cardiol. 2013; 62(10): 940-941, doi: 10.1016/j.jacc.2013.05.021, indexed in Pubmed: 23747780.

18. Franchi F, Rollini F, Cho JR, et al. Impact of Escalating Loading Dose Regimens of Ticagrelor in Patients With ST-Segment Elevation Myocardial Infarction Undergoing Primary Percutaneous Coronary Intervention: Results of a Prospective Randomized Pharmacokinetic and Pharmacodynamic Investigation. JACC Cardiovasc Interv. 2015; 8(11): 1457-1467, doi: 10.1016/j. jcin.2015.02.030, indexed in Pubmed: 26404199.

19. Kubica J, Adamski P, Ostrowska M, et al. Morphine delays and attenuates ticagrelor exposure and action in patients with myocardial infarction: the randomized, double-blind, placebo-controlled IMPRESSION trial. Eur Heart J. 2016; 37(3): 245-252, doi: 10.1093/eurheartj/ehv547, indexed in Pubmed: 26491112.

20. Parodi G, Xanthopoulou I, Bellandi B, et al. Ticagrelor crushed tablets administration in STEMI patients: the MOJITO study. J Am Coll Cardiol. 2015; 65(5): 511-512, doi: 10.1016/j. jacc.2014.08.056, indexed in Pubmed: 25660931.

21. Venetsanos D, Sederholm Lawesson S, Swahn E, et al. Chewed ticagrelor tablets provide faster platelet inhibition compared to integral tablets: The inhibition of platelet aggregation after administration of three different ticagrelor formulations (IPAADTica) study, a randomised controlled trial. Thromb Res. 2017; 149: 88-94, doi: 10.1016/j.thromres.2016.10.013, indexed in Pubmed: 27773347.

22. Aungraheeta R, Conibear A, Butler M, et al. Inverse agonism at the P2Y12 receptor and ENT1 transporter blockade contribute 


\section{Cardiology Journal}

to platelet inhibition by ticagrelor. Blood. 2016; 128(23): 2717 -2728, doi: 10.1182/blood-2016-03-707844, indexed in Pubmed: 27694321.

23. Nanhwan MK, Ling S, Kodakandla M, et al. Chronic treatment with ticagrelor limits myocardial infarct size: an adenosine and cyclooxygenase-2-dependent effect. Arterioscler Thromb Vasc Biol. 2014; 34(9): 2078-2085, doi: 10.1161/ATVBAHA.114.304002, indexed in Pubmed: 25012137.

24. Khan JN, Greenwood JP, Nazir SA, et al. Infarct Size Following Treatment With Second- Versus Third-Generation P2Y12 Antagonists in Patients With Multivessel Coronary Disease at ST-Segment Elevation Myocardial Infarction in the CvLPRIT Study. J Am Heart Assoc. 2016; 5(6), doi: 10.1161/JAHA.116.003403, indexed in Pubmed: 27247336.

25. Armstrong PW, Zheng Y, Westerhout CM, et al. Corrigendum to "Reduced dose tenecteplase and outcomes in elderly ST-segment elevation myocardial infarction patients: Insights from the Strategic Reperfusion Early After Myocardial infarction trial" [Am Heart J 169/6 (2015) 890-898]. Am Heart J. 2017; 184: 157, doi: 10.1016/j.ahj.2017.01.005, indexed in Pubmed: 28224932.

26. Laine $\mathrm{M}$, Panagides V, Frère $\mathrm{C}$, et al. Platelet reactivity inhibition following ticagrelor loading dose in patients undergoing percutaneous coronary intervention for acute coronary syndrome. J Thromb Haemost. 2019; 17(12): 2188-2195, doi: 10.1111/ jth.14592, indexed in Pubmed: 31351022.

27. Sun J, Xiang Q, Li C, et al. Efficacy and Safety of Novel Oral P2Y12 Receptor Inhibitors in Patients With ST-Segment Elevation Myocardial Infarction Undergoing PCI: A Systematic Review and Meta-Analysis. J Cardiovasc Pharmacol. 2017; 69(4): 215-227, doi: 10.1097/FJC.0000000000000459, indexed in Pubmed: 28045759.

28. Ducrocq G, Schulte PJ, Becker RC, et al. Association of spontaneous and procedure-related bleeds with short- and long-term mortality after acute coronary syndromes: an analysis from the PLATO trial. EuroIntervention. 2015; 11(7): 737-745, doi: 10.4244/EIJY14M09 11, indexed in Pubmed: 25254357.
29. Lee CH, Cheng CL, Kao Yang YH, et al. Cardiovascular and bleeding risks in acute myocardial infarction newly treated with ticagrelor vs. clopidogrel in Taiwan. Circ J. 2018; 82(3): 747-756, doi: 10.1253/circj.CJ-17-0632, indexed in Pubmed: 29081474.

30. Wang HY, Li Yi, Xu XM, et al. Impact of baseline bleeding risk on efficacy and safety of ticagrelor versus clopidogrel in Chinese patients with acute coronary syndrome undergoing percutaneous coronary intervention. Chin Med J (Engl). 2018; 131(17): 2017-2024, doi: 10.4103/0366-6999.239306, indexed in Pubmed: 30127210.

31. Bonello L, Camoin-Jau L, Arques S, et al. Adjusted clopidogrel loading doses according to vasodilator-stimulated phosphoprotein phosphorylation index decrease rate of major adverse cardiovascular events in patients with clopidogrel resistance: a multicenter randomized prospective study. J Am Coll Cardiol. 2008; 51(14): 1404-1411, doi: 10.1016/j.jacc.2007.12.044, indexed in Pubmed: 18387444.

32. Wang XD, Zhang DF, Zhuang SW, et al. Modifying clopidogrel maintenance doses according to vasodilator-stimulated phosphoprotein phosphorylation index improves clinical outcome in patients with clopidogrel resistance. Clin Cardiol. 2011; 34(5): 332-338, doi: 10.1002/clc.20884, indexed in Pubmed: 21538380.

33. Wang Xd, Zhang Df, Liu Xb, et al. Modified clopidogrel loading dose according to platelet reactivity monitoring in patients carrying $\mathrm{ABCB} 1$ variant alleles in patients with clopidogrel resistance. Eur J Intern Med. 2012; 23(1): 48-53, doi: 10.1016/j. ejim.2011.07.016, indexed in Pubmed: 22153531.

34. Lomakin N, Rudakova A, Buryachkovskaya L, et al. Cost-effectiveness of platelet function-guided strategy with clopidogrel or ticagrelor. Eur Cardiol. 2019; 14(3): 175-178, doi: 10.15420/ ecr.2018.29.2, indexed in Pubmed: 31933687.

35. Sibbing D, Aradi D, Jacobshagen C, et al. Guided de-escalation of antiplatelet treatment in patients with acute coronary syndrome undergoing percutaneous coronary intervention (TROPICAL-ACS): a randomised, open-label, multicentre trial. Lancet. 2017; 390(10104): 1747-1757, doi: 10.1016/S0140-6736(17)32155-4, indexed in Pubmed: 28855078. 